This communication is published with the approval of the Chief Medical Director. The statements published by the author do not necessarily reflect the policy of the Veterans Administration.

Robert L. Evans

Veterans Administration Hospital, and

Department of Mechanics and Materials, University of Minnesota, Minneapolis, Minn. Sept. 21 .

'Shemin, D., and Rittenberg, D., J. Biol. Chem., 166, 627 (1946). ${ }^{2}$ London, I. M., Shemin, D., West, R., and Rittenberg, D., J. Biol. Chem., 179, 463 (1949).

${ }^{3}$ Amatuzio, D. S., and Evans, R. L., Nature, 171, 797 (1953).

- Berlin, N. I., Lawrence, J. H., and Lee, H. C., Science, 114, 385 (1951).

${ }^{5}$ London, I. M., West, R., Shemin, D., and Rittenberg, D., J. Biol. Chem., 184, 351 (1950).

'Wintrobe, M. M., "Clinical Hematology", 2nd edit., 38 and 48 (Lea and Febriger, Philadelphia, 1946). 'Finch, C. A., Gibson, II, J. G., Peacock, W. C., and Fluharty, R. G.,
Blood, 4, 905, Table 3 (1949).

\section{Architomy in a Species of Convoluta}

ON the south-eastern coasts of southern Africa, there occurs a species of Convoluta which shows the rare phenomenon of asexual reproduction by architomy or scissiparity.

Specimens of this species have been collected by one of us (W. M.) from various localities between Cape Padrone and Inyack Island, at the entrance to Delagoa Bay. The worm was first noticed by Warren', whose identification with the well-known Convoluta roscoffensis was accepted without comment by von Graff ${ }^{2}$. Wager ${ }^{3}$ described rather more fully some of the peculiarities and habits of the worm. $\mathrm{He}$ mentions several points of difference from the European species and directs attention to the fact that he could find "no signs of any sexual organs either in the living animal or in microtome sections". In serial sections prepared by one of us (E. M.), of twelve specimens with recognizable germ cells, no trace could be found of the "kurzen, glockenförmigen Penis" which von Graff" described for C. roscoffensis. Several living specimens have been examined by W. M. in an attempt to find rudimentary traces, but none was found although moving sperm were seen in the vas deferens. Westblad ${ }^{5}$ has described a species of Convoluta without any form of male organ apart from a fine canal, and it would appear that the South African specimens belong to such a species and so are different from $C$. roscoffensis and certainly constitute a new species of which a description will be published elsewhere. Also, as Warren ${ }^{1}$ has already observed, the mouth lies farther forward than it does in the European species and much nearer to the statocyst than this organ is to the tip.

Populations on open ocean beaches usually contain very long individuals assorted with short ones, which have young heads (without frontal organs) and tails. The long individuals may show lines of constriction at various levels which are paler than the rest of the body. One specimen was seen to divide, and the portions which separate off, though lacking head and tail, were quite capable of moving around, apparently in a normal manner. It appeared merely to break into two without reference to the lines of constriction mentioned. Wager ${ }^{3}$ has already described this phenomenon, but his observations seem to have been overlooked by all later workers and have not passed into any of the treatises on the group. His paper is mentioned in the Zoological Record (50, Vermes, p. 21, No. 439), but the contents are summarily given as "habits". In view of the considerable interest and importance of his observations they are quoted in full:

"The reproduction is the most peculiar feature of the animal. After repeated observations I could find no signs of any sexual organs either in the living animal or in microtome sections. Whether sexual reproduction has been discarded altogether, it is, of course, difficult to say, but in any case there is a prolific means of asexual reproduction which, I believe, has not previously been reported, that is, by the severance of parts of the animal, each part being able to form itself into a new animal. This severance may be due to accident, such as being dashed against the sand, stones, etc., in which case the delicate animal comes off badly, but even the smallest pieces appear able to regenerate. I have divided a single animal into four parts, and aiter about two hours each part had assumed the elongate ribbon shape of the mature animal, swimming about the whole time. This method of reproduction by the regeneration of parts is of course well known in many animals such as Hydra, but it is only resorted to in case of accident. The animals concerned cannot be said to reproduce by this method. In the case of Convoluta, however, the delicate nature of the animal is one of its peculiar features, the slightest touch causing puts out protuberances which gradually elongate, and then become puts out protuberances which gradually elongate, and then become complete, so that this is hardly a case of budding in so far as the protrusions are not formed by growth."

This phenomenon of architomy is common among Tricladida paludicola. Catenulida and Microstomida divide paratomically. The method is unrecorded for Acoela, though Dr. Erich Shultz of Kiel has independently re-discovered the phenomenon in some Acoela from the Baltic. He has frequently mentioned his observations in letters to one of us (E.M.), but has not yet published them.

Ernesto Marcus

Faculdade de Filosofia, Ciências e Letras, Universidade de São Paulo, São Paulo, Brazil.

William Macnate

Department of Zoology, Rhodes University,

Grahamstown, South Africa.

1 Warren, E., Ann. Natal Mus., 1, 105 (1906).

"von Graff, L., "Bronns Klassen...", ref. No. 1144 (flrst line interchanged with that of 1172) (1912).

${ }_{3}$ Wager, A. H., Rep. S. Afr. Assoc. Adv. Sci., 10, 223 (1913).

"von Graff, L., "Das Tierreich", 23, Turbellaria acoela (1905).

'Westblad, E., Ark. Zoologi, 38, A 1, 1 (1946).

\section{Contact Chemoreceptors of Blowfly Tarsi}

THE contact chemoreceptors of blowfly tarsi have been the subject of much experimental work since the existence of tarsal taste sense in the Calliphoridae was discovered by Minnich ${ }^{1}$; the literature has been reviewed elsewhere ${ }^{2,3}$. The receptors concerned have not been positively identified and no details of the structure of the receptor surface have been reported.

The tarsal contact chemoreceptors of Protophormia terraenovae R.-D. are located in two ventral rows on each tarsal segment, adjacent to two rows of stout spines which protect the thin-walled receptors from mechanical damage. There are approximately 260 chemoreceptors on each fore-tarsus, and 150 on each middle- and hind-tarsus, in both sexes. The receptors are $40-60 \mu$ long except at the distal extremity of each segment, where receptors $150 \mu$ and $240 \mu$ long are located.

Each chemoreceptor is a flexible, hollow seta characteristically innervated by a spindle-shaped 